\title{
Numerical Characterization of Concrete Heterogeneity
}

\author{
Roque Luiz, Pitangueira ${ }^{\mathrm{a}}$, Raul Rosas e Silva ${ }^{\mathrm{b}}$ * \\ ${ }^{a}$ Department of Structural Engineering, Federal University of Minas Gerais \\ Av. do Contorno, 842, 30110-060 Belo Horizonte - MG, Brazil \\ ${ }^{\mathrm{b}}$ Department of Civil Engineering, Pontifical Catholic University of Rio de Janeiro \\ Rua Marquês de São Vicente, 225, 22453-900 Rio de Janeiro - RJ, Brazil
}

Received: September 27, 2001; Revised: July 10, 2002

\begin{abstract}
In this paper, a finite element model including both material heterogeneity and size effects is presented. The concrete is considered as a statistical combination of constituent phase with different properties (aggregate, mortar and interface material). The material point response is based on a combination of the random occurrence of the solid phases in the structural volume as well as on the differences of structural response due to the size effect. Such combination allows for higher or lower heterogeneity corresponding to smaller or larger structural size. Simulations of the material heterogeneity and associated size effect in a computationally efficient and simple manner show good qualitative agreement with available experimental results for the three-point bending and Brazilian split tests.
\end{abstract}

Keywords: heterogeneity, size effect, concrete, finite element method

\section{Introduction}

The existence of the size effect phenomenon is as old as the Solid Mechanics. The question was discussed by Galileo Galilei in the book Discorsi e Dimostrazioni Matematiche Intorno a Due Nuove Scienze ${ }^{1}$.

In concrete structures, however, the consideration of size effect has received attention in only recent years. Experimental evidence ${ }^{2-5}$ has shown a significant influence of size in the structural strength and brittleness. Bazant and Pfeiffer ${ }^{2}$ studied such phenomenon in structures subject to three-point bending and direct tension. The reduction of the nominal strength with the size was observed in the tests. The question related to the brittleness was also investigated ${ }^{3}$ and the equilibrium paths obtained in the tests revealed a more brittle behavior as the structural member becomes larger in size.

Many theoretical models have been proposed to simulate the size effect in concrete structures ${ }^{6-8}$. However, the material heterogeneity, which seems to be the main factor influencing the size effect, is not taken into consideration. In some models the introduction of heterogeneity is made by discretizing the material microstructure in finite elements $^{9-11}$. The use of such models is limited to small structures due to the large amount of computer time required.

In this paper, a novel finite element model including both heterogeneity and size effects is presented. The concrete heterogeneity is considered by a statistical combination of the constituent materials with different properties (aggregate, mortar matrix and interface material). The size effect is taken into account by combining a local constitutive response, related to one of the material constituents, with a law representing the mixture and valid for structural volumes larger than the material inhomogeneities. The proposed model preserves the usual characteristics of the finite element method and allows for simulating the size effect phenomenon in a computationally efficient and simple manner.

\section{Heterogeneity Simulation}

Finite element models of crack propagation in concrete can be discrete or smeared. The smeared crack approach

*e-mail: roque@dees.ufmg.br, raul@civ.puc-rio.br 
considers the cracks as regions of damaged material in the finite element. The process of damage propagation can be followed by proper modification of the stress-strain relations. This appears to be a more convenient tool for the approximate modelling of the propagation of cracking patterns occurring in concrete structures.

Using the smeared approach, the material heterogeneity can be accounted for in a simple manner, by assigning different stress-strain relations to each integration point.

In the usual models, the constitutive relation is the same for all integration points, in the start of the analysis. With deformation, this relation is modified to account for damage in tension and compression. In the present study, the initial properties of each integration point are associated to the components of concrete.

The mechanical properties of concrete are related to the low strength of the interface region between the mortar and the aggregate. Solid concrete can be represented as a threephase material: aggregate, mortar matrix and interface material.

Using all integration points of the finite element mesh to define a statistical space, a random number is generated for each point. With that number and assuming an uniform probability model, one of the three phases of the heterogeneity mixture is chosen to represent the point, based on the volume fraction of each phase (Fig. 1).

In spite of the heterogeneity model simplicity, the local constitutive law (of an integration point) cannot be considered as a stress-strain relation of one of the concrete con- stituents. That law should be a combination of the constitutive (local) and structural (global) response to allow for size effect to be considered.

Such a combination can be performed by defining an index of heterogeneity $(\mathrm{IH})$ as the ratio between the volume of a basic cell $\left(\mathrm{V}_{\mathrm{CB}}\right)$, representing the material inhomogeneities, and the finite element volume $\left(\mathrm{V}_{\mathrm{PI}}\right)$, representing the integration point ${ }^{14}$ :

$$
I H=\frac{V_{C B}}{V_{P I}}
$$

Using the heterogeneity index, the integration point constitutive law can be obtained by combining the solid phase (aggregate, mortar or interface) properties of the heterogeneity model with the properties of the basic cell representing the mixture law. Such a combination allows for higher or lower heterogeneity corresponding to smaller or larger structural size.

For a constitutive property $\mathrm{P}$ the combination can be written as ${ }^{14}$

$$
P_{P I}=I H \cdot P_{L C}+(1-I H) \cdot P_{L E}
$$

where $\mathrm{P}_{\mathrm{PI}}$ represents the value of the constitutive property $\mathrm{P}$ at integration point $\mathrm{PI}, \mathrm{P}_{\mathrm{LC}}$ represents such property locally measured (local constitutive law) and $\mathrm{P}_{\mathrm{LE}}$ represents the value of the property in the structural level.

Such a combination contemplates the size effect since a

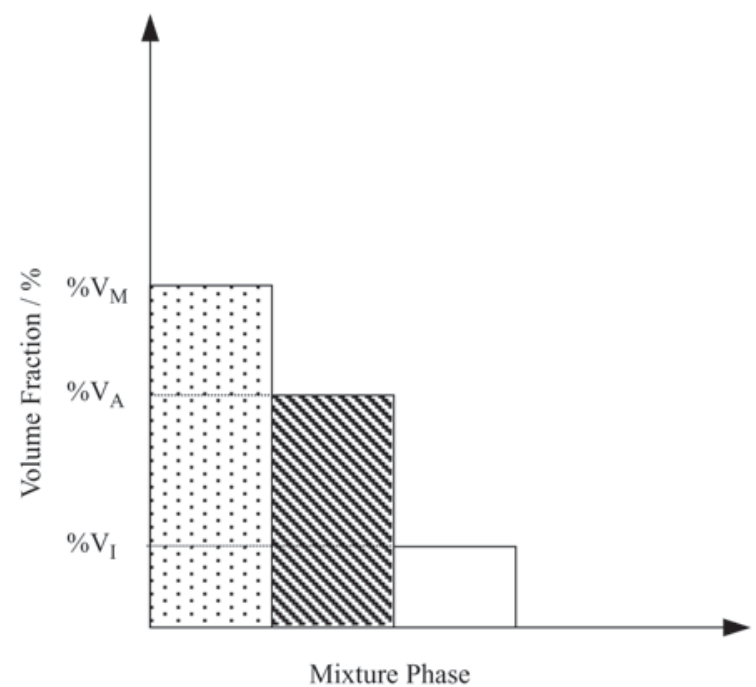

AN Aggregate

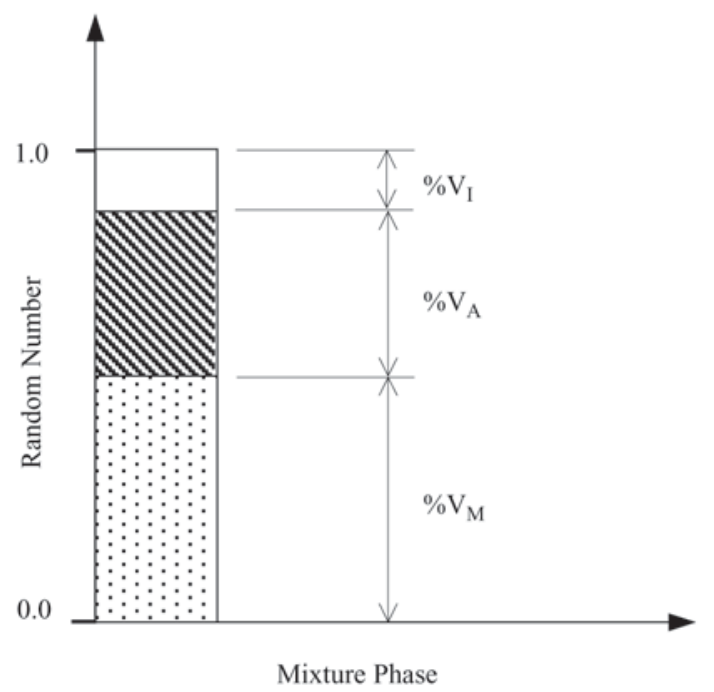

Matrix Interface

Figure 1. Heterogeneity simulation with constant probability. 
property $\mathrm{P}$ measured in the structural and constitutive level has very different values. The heterogeneity randomness is also represented because the property $\mathrm{P}_{\mathrm{LC}}$ can be associated to any mixture constituent phase. Fig. 2 illustrates the idea.

Constitutive behavior of each phase and its combinations, can be described by a simple stress-strain relation (Fig. 3).

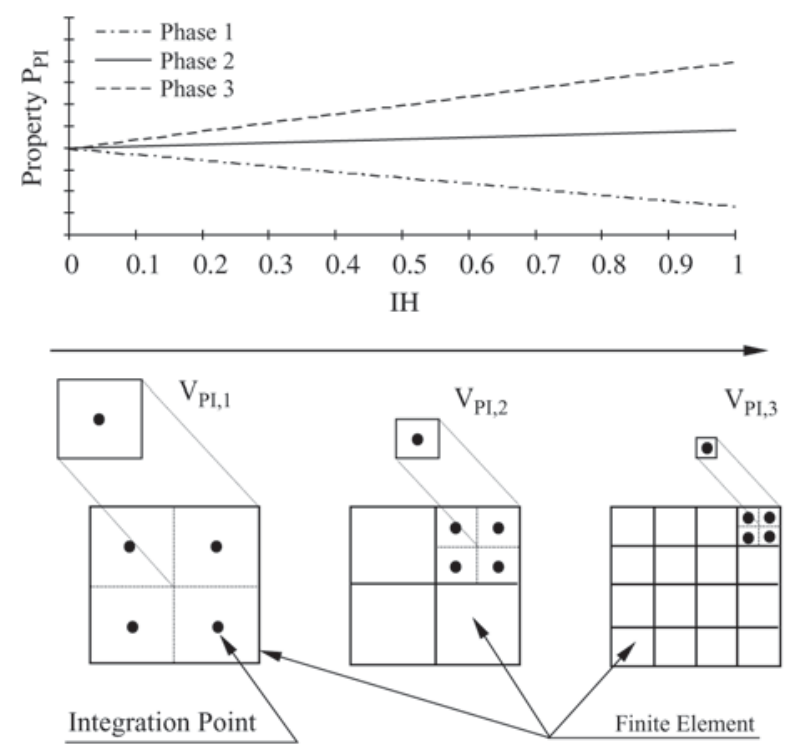

Figure 2. Proposed model to heterogeneity.
Using a bilinear relationship to describe compression and tensile behavior, the mechanical parameters are: elastic modulus of the ascending branch $\left(\mathrm{E}_{0}\right)$, elastic modulus of the descending branch $\left(E_{2}\right)$, axial compression strength $\left(f_{c}\right)$, axial tensile strength $\left(f_{t}\right)$ and fracture energy per unit volume $\left(g_{f}\right)$.

In order to obtain the equilibrium paths in the nonlinear analysis, the generalized displacement control method ${ }^{12}$ was adopted.

\section{Simulation Results of the Brazilian Split-Cylinder Tests}

The Brazilian split-cylinder test has been modeled for different structural sizes, corresponding to different heterogeneity indexes.

To represent the local behavior of each phase (aggregate, matrix and interface), bilinear relationships are adopted, with the mechanical properties shown in Table 1.

The properties of the matrix correspond to those of the

Table 1. Properties used in the model.

\begin{tabular}{lcccccc}
\hline Constituent & $\begin{array}{c}\mathrm{f}_{\mathrm{c}} \\
(\mathrm{MPa})\end{array}$ & $\begin{array}{c}\mathrm{f}_{\mathrm{t}} \\
(\mathrm{MPa})\end{array}$ & $\mathrm{v}$ & $\begin{array}{c}\mathrm{E}_{0} \\
(\mathrm{MPa})\end{array}$ & $\begin{array}{c}\mathrm{E}_{2} \\
(\mathrm{MPa})\end{array}$ & $\begin{array}{c}\mathrm{g}_{\mathrm{f}} \\
(\mathrm{MPa})\end{array}$ \\
\hline Matrix & 48.0 & 3.4 & 0.2 & $3.2 \mathrm{e} 4$ & $-3.2 \mathrm{e} 3$ & $1.81 \mathrm{e}-3$ \\
Aggregate & 80.0 & 16 & 0.2 & $1.0 \mathrm{e} 5$ & $-1.0 \mathrm{e} 4$ & $1.28 \mathrm{e}-2$ \\
Interface & 13.0 & 2.0 & 0.2 & $1.7 \mathrm{e} 4$ & $-1.7 \mathrm{e} 3$ & $1.18 \mathrm{e}-3$ \\
Mixture & 40.0 & 3.8 & 0.2 & $4.4 \mathrm{e} 4$ & $-4.4 \mathrm{e} 3$ & $1.64 \mathrm{e}-3$ \\
\hline
\end{tabular}

\section{TENSION}

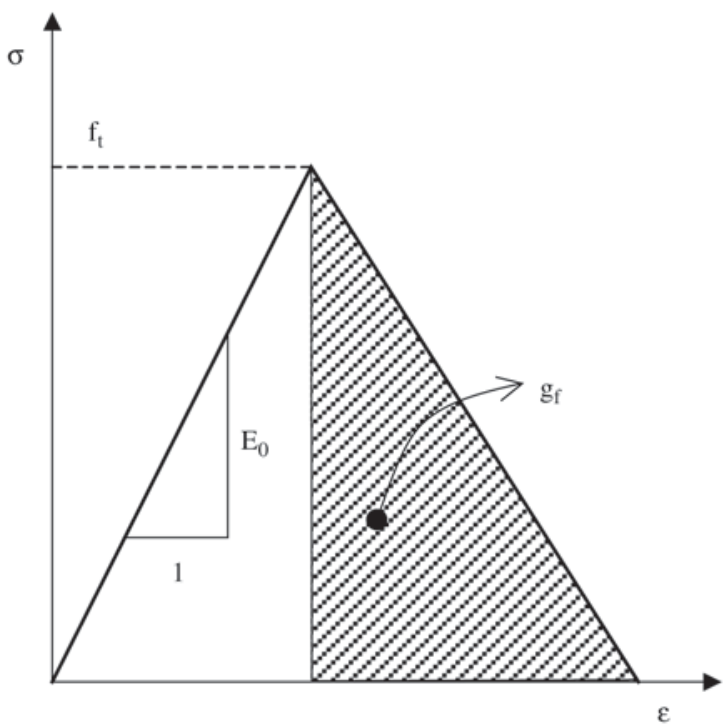

Figure 3. Stress-Strain relations used in the constitutive modelling. 
mortar of Bazant and Pffeifer ${ }^{2}$. The aggregate phase is represented as the basalt of Monteiro ${ }^{13}$ and the interface phase is simulated with the test results of Monteiro ${ }^{13}$. The concrete mixture adopted has the proportion of $30 \%$ of aggregate, $55 \%$ of matrix and $15 \%$ of interface. The mixture properties are also shown in Table 1. On the basis of the above mentioned test results, the bilinear constitutive law parameters of Table 1 are obtained ${ }^{14}$.

Figure 4 shows a mesh of four-node quadrilateral elements used in the analysis of a cylinder of diameter $\mathrm{d}=150 \mathrm{~mm}$ and thickness of $100 \mathrm{~mm}$, with an initial central crack. Four integration points in each element and plane stress conditions are considered.

By taking the smallest finite element to represent the maximum degree of heterogeneity or the smallest beam $\left(\mathrm{IH} \approx 1.0\right.$ or $\left.\mathrm{V}_{\mathrm{CB}} \approx \mathrm{V}_{\mathrm{PI}}\right)$, the variation of the basic cell volume $\left(\mathrm{V}_{\mathrm{CB}}\right)$ allows for size effect to be analised for different heterogeneity indexes (IH) or different structural sizes. The simulated equilibrium paths, obtained with the generalized displacement control method ${ }^{12}$, reference load of $-30 \mathrm{kN}$, tolerance of $10^{-4}$ and different heterogeneity indexes (IH) are shown in Fig. 5.

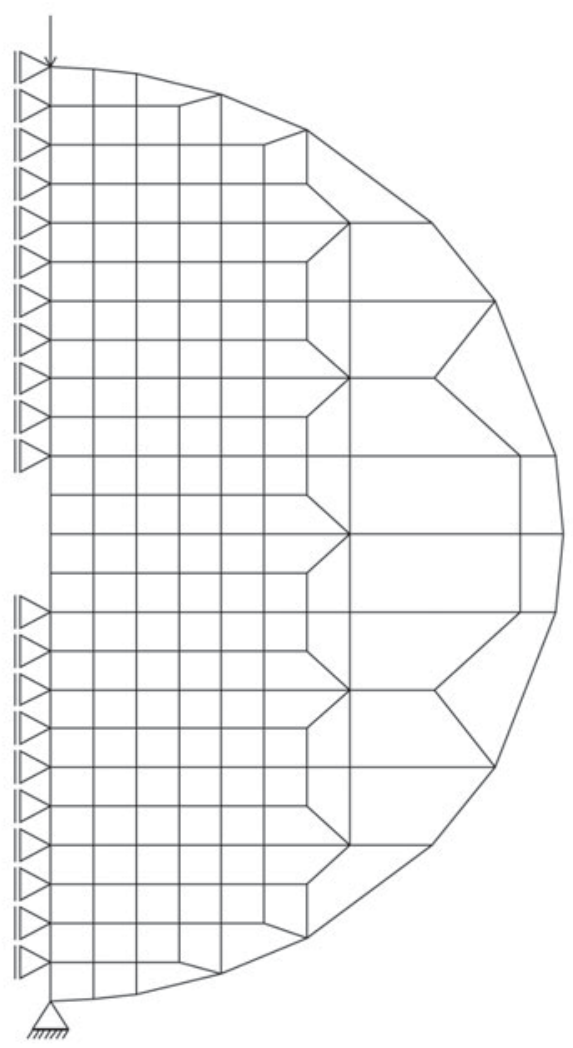

Figure 4. Finite element mesh used in the Brazilian split-cylinder tests model.

\section{Simulation Results of the Three-Point Bending Tests}

A concrete beam of dimensions $90 \times 36 \times 36 \mathrm{~mm}$ with a notch of dimensions $2.5 \times 6.0 \mathrm{~mm}$ is taken as reference for the size effect analysis in three-point bending tests. A mesh of four-node quadrilateral elements used in the analysis is shown in Fig. 6. Four integration points in each element and plane stress conditions are adopted.

The mixture proportions as well as the mechanical properties to the bilinear relationships for the constituents and the mixture are the same of the previous example (brazilian split-cylinder test). The equilibrium paths obtained with reference load of $-1.0 \mathrm{kN}$ and tolerance of $10^{-4}$ are shown in Fig. 7.

Two different situations are observed in the descending branch of the equilibrium paths obtained (Figs. 5 and 7). A more fragile behavior is observed in the case of larger structures (more homogeneous structures with IH tending to 0.0 ). On the other hand a more ductile behavior is observed in the case of smaller structures, (more heterogeneous with IH tending to 1.0).

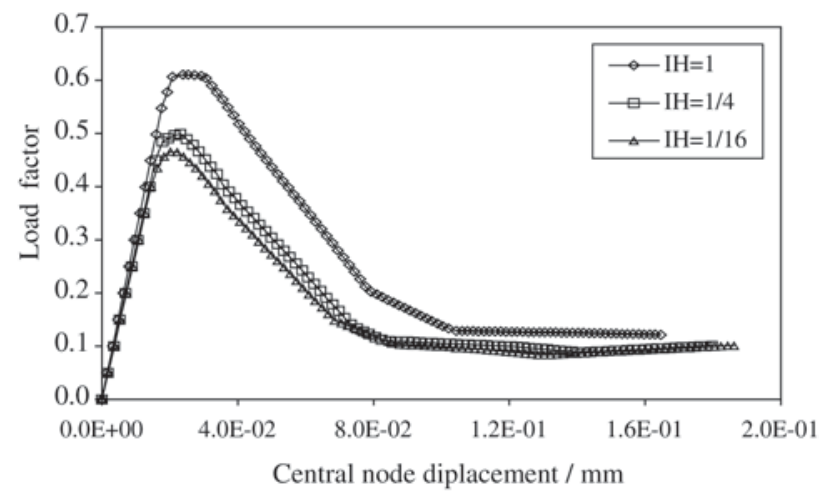

Figure 5. Equilibrium paths of the Brazilian split-cylinder tests.

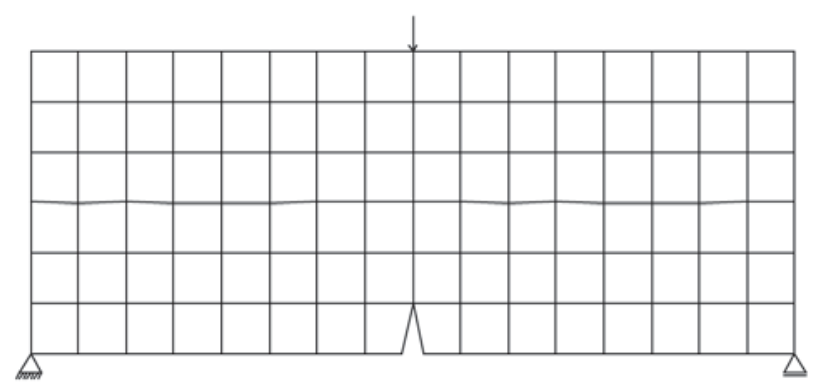

Figure 6. Finite element mesh used in the three-point bending tests model. 


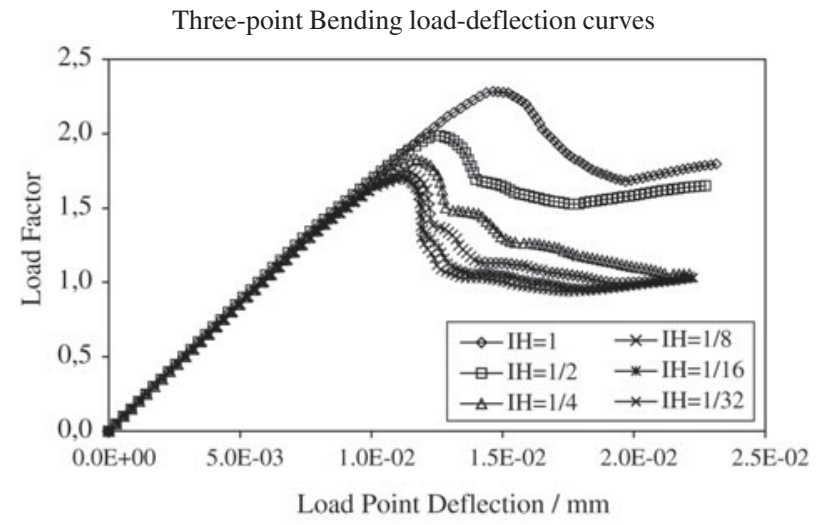

Figure 7. Load Factor versus Load Point Deflection curves.

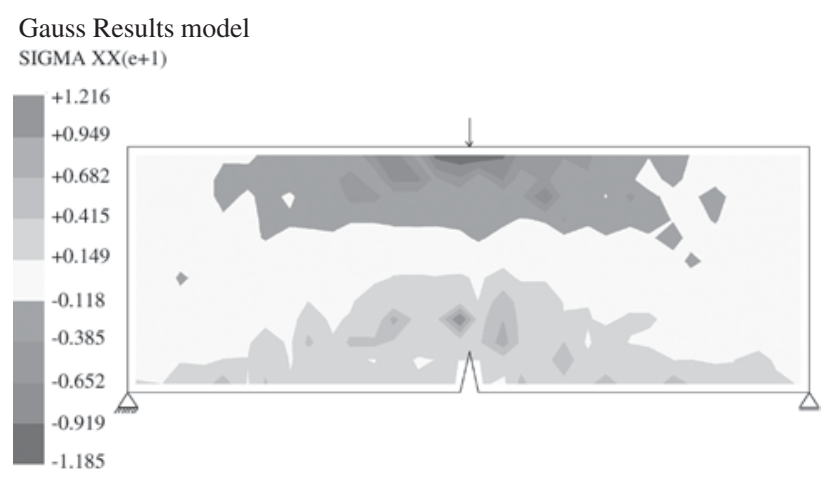

Figure 8. Stress Contour for the Three-Point Bending.

The influence of size in the structure strength is also observed. As shown in Fig. 5 and 7, the load factor decreases as the heterogeneity index ( $\mathrm{IH}$ ) decreases, indicating smaller strength in the case of larger structures.

This numerical evidence shows a good qualitative agreement with experimental results of various researchers ${ }^{2-5}$. For a quantitative analysis, more test results for the individual components of concrete are needed.

The proposed model allows for better understanding the influence of heterogeneity on the nonlinear response of concrete structures. As it can be seen in Fig. 8, the stress contour for the three-point bending model appears to be a more realistic representation than the one that would be obtained with the homogeneous approach.

\section{Final Remarks}

In this paper, a finite element model including both heterogeneity and size effects has been presented. The concrete initial heterogeneity and the nonlinearities in the deformation process are considered in a smeared manner, al- lowing for simple simulation of the structural response.

Simulations of the material heterogeneity in a computationally efficient and simple manner show a good agreement between qualitative experimental and proposed model results.

This model appears to be a useful tool for the design of reinforced concrete structures when an estimate of the sensitivity of the brittleness and strength with respect to size is required.

Further work is necessary to develop a three-dimensional model which takes into account the spatial distribution and interaction of the constituent materials.

\section{References}

1. Galileo, G.L. "Discorsi e Dimostrazioni Matematiche Intorno à Due Nuove Scienze", English version by Weston, T., London, 1730.

2. Bazant, Z.P.; Pfeiffer, P.A. Determination of Fracture Energy from Size Effect and Brittleness Number, ACI Materials Journal, v. 84, p. 463-480, 1987.

3. Gettu, R.; Bazant, Z.P.; Karr, M.E., Fracture Properties and Brittleness of High-Strength Concrete, ACI Materials Journal, v. 87, p. 608-618, 1990.

4. Perdikaris, P.C.; Romeo, A. Size Effect on Fracture Energy of Concrete and Stability Issues in Three-Point Bending Fracture Toughness Testing, ACI Materials Journal, v. 92, p. 483-496, 1995.

5. Chang, T.P.; Shieh, M.M., Fracture Properties of Lightweight Concrete, Cement and Concrete Research, v. 26, n. 2, p. 181-188, 1996.

6. Bazant, Z.P.; Cedolin, L. Stability of Structures - Elastic, Inelastic, Fracture and Damage Theories, Oxford University Press, New York, 1991.

7. Hillerborg, A.; Modéer, M.; Peterson, P. Analysis of Crack Formation and Crack Growth in Concrete by Means of Fracture Mechanics and Finite Elements, Cement and Concrete Research, v. 6, p. 773-782, 1976.

8. Bazant, Z.P.; Lin, F.B., Nonlocal Smeared Cracking Model for Concrete Fracture, Journal of the Engineering Mechanics (ASCE), v. 114, n. 11, p. 2493-2510, 1988.

9. Burt, N.J.; Dougill, J.W., Progressive Failure in a Model Heterogeneous Medium, Journal of the Engineering Mechanics Division (ASCE), v. 103, n. EM3, p. 365-376, 1977.

10. Schlangen, E. Experimental and Numerical Analysis of Fracture Processes in Concrete, Heron, v. 38, n. 2, pp. 1-117, 1993.

11. Vonk, R.A. A Micromechanical Investigation of Softening of Concrete Loaded in Compression, Heron, v. 38, n. 3, pp. 1-94, 1993.

12. Yang, Y.B.; Kuo, S.R. Theory \& Analysis of Nonlinear Framed Structures, Prentice Hall, Singapore, 1994. 
13. Monteiro, P.J.M. Microstructure of Concrete and its Influence on the Mechanical Properties, Ph.D. Thesis, Department of Civil Engineering, University of California, Berkeley, 1985.
14. Pitangueira, R.L.S. Mechanics of Concrete Structures considering Size Effects and Heterogeneitry, (in Portuguese), Ph.D. Thesis, Department of Civil Engineering, PUC-Rio, 1998. 